\title{
Experimental Chemotherapy for Chagas Disease: A Morphological, Biochemical, and Proteomic Overview of Potential Trypanosoma cruzi Targets of Amidines Derivatives and Naphthoquinones
}

\author{
Solange L. de Castro, Denise G. J. Batista, Marcos M. Batista, Wanderson Batista, \\ Anissa Daliry, Elen M. de Souza, Rubem F. S. Menna-Barreto, Gabriel M. Oliveira, \\ Kelly Salomão, Cristiane F. Silva, Patricia B. Silva, and Maria de Nazaré C. Soeiro
}

Laboratório de Biologia Celular, Instituto Oswaldo Cruz, Fundação Oswaldo Cruz, 21040-900 Rio de Janeiro, RJ, Brazil

Correspondence should be addressed to Solange L. de Castro, solange@ioc.fiocruz.br

Received 4 January 2011; Revised 25 February 2011; Accepted 21 March 2011

Academic Editor: Hemanta K. Majumder

Copyright () 2011 Solange L. de Castro et al. This is an open access article distributed under the Creative Commons Attribution License, which permits unrestricted use, distribution, and reproduction in any medium, provided the original work is properly cited.

\begin{abstract}
Chagas disease (CD), caused by Trypanosoma cruzi, affects approximately eight million individuals in Latin America and is emerging in nonendemic areas due to the globalisation of immigration and nonvectorial transmission routes. Although CD represents an important public health problem, resulting in high morbidity and considerable mortality rates, few investments have been allocated towards developing novel anti-T. cruzi agents. The available therapy for CD is based on two nitro derivatives (benznidazole $(\mathrm{Bz})$ and nifurtimox $(\mathrm{Nf})$ ) developed more than four decades ago. Both are far from ideal due to substantial secondary side effects, limited efficacy against different parasite isolates, long-term therapy, and their well-known poor activity in the late chronic phase. These drawbacks justify the urgent need to identify better drugs to treat chagasic patients. Although several classes of natural and synthetic compounds have been reported to act in vitro and in vivo on T. cruzi, since the introduction of $\mathrm{Bz}$ and Nf, only a few drugs, such as allopurinol and a few sterol inhibitors, have moved to clinical trials. This reflects, at least in part, the absence of well-established universal protocols to screen and compare drug activity. In addition, a large number of in vitro studies have been conducted using only epimastigotes and trypomastigotes instead of evaluating compounds' activities against intracellular amastigotes, which are the reproductive forms in the vertebrate host and are thus an important determinant in the selection and identification of effective compounds for further in vivo analysis. In addition, due to pharmacokinetics and absorption, distribution, metabolism, and excretion characteristics, several compounds that were promising in vitro have not been as effective as $\mathrm{Nf}$ or $\mathrm{Bz}$ in animal models of T. cruzi infection. In the last two decades, our team has collaborated with different medicinal chemistry groups to develop preclinical studies for CD and investigate the in vitro and in vivo efficacy, toxicity, selectivity, and parasite targets of different classes of natural and synthetic compounds. Some of these results will be briefly presented, focusing primarily on diamidines and related compounds and naphthoquinone derivatives that showed the most promising efficacy against T. cruzi.
\end{abstract}

\section{Chagas Disease and Its Treatment}

Chagas disease $(\mathrm{CD})$ is caused by the intracellular obligatory parasite Trypanosoma cruzi. The life cycle of this parasite involves haematophagous triatomine insect vectors, diverse vertebrate mammalian hosts, and different developmental forms. Briefly, after bloodstream trypomastigotes are ingested by an insect, they are converted to epimastigotes, which proliferate and differentiate into metacyclic forms within the posterior intestine of the triatomine. These infective forms, released within the faeces and urine, can invade vertebrate cells and undergo another round of differentiation into the intracellular amastigote forms, which proliferate and then transform back to trypomastigotes, the form that disseminates the infection. CD is the major cause of infectious cardiopathy and represents an important public 
health problem; it is broadly dispersed in 18 developing countries in South and Central America [1]. It affects approximately eight million people in Latin America, of whom $30-40 \%$ either have or will develop cardiomyopathy, digestive megasyndromes, or both [2]. CD transmission occurs primarily via the vector $(90 \%)$ but may also occur through blood transfusion and congenital transmission as well as laboratory accidents [3], organ transplantation [4], and ingestion of contaminated food and beverages [5]. Recently, CD has become a major concern due to globalisation, which results in immigration of infected individuals to nonendemic regions, thus spreading the disease [6]. Although both vectorial and transfusional transmission have sharply declined in the past 20 years due to Southern Cone countries' policies, several challenges still need to be overcome, including those related to sustainable public health initiatives, vector control strategies, and educational approaches $[7,8]$. Thus, because epidemiological and transmission control characteristics of CD may vary according to each country's ecological conditions and adopted health policies, continuous epidemiological survey in conjunction with efficient and universal therapy of the infected individuals must be performed to maintain and even reduce the number of new acute cases [9].

$\mathrm{CD}$ affects mainly poor, rural and forgotten populations and has two consecutive clinical phases: the acute phase that appears shortly after infection, which ranges from flu-like symptoms to intense myocarditis (in approximately $10 \%$ of infected people), and the chronic symptomatic phase, which develops in approximately one-third of infected individuals after an asymptomatic period (indeterminate form) lasting years or decades $[10,11]$. The main clinical manifestations of the chronic stage include cardiac and/or gastrointestinal involvement, and the variability in $\mathrm{CD}$ outcome has been related to host response and parasite heterogeneity [12]. Although its pathology is poorly understood, growing evidence has shown that parasitic persistence within the target organs associated with an unregulated host immune response is involved in pathogenesis, disease progression, and outcome $[1,13,14]$.

Since its discovery by Chagas more than a hundred years ago [15], CD still poses many challenges, including its peculiar epidemiology, characterised by a variety of risk factors (diverse vectors and reservoirs and different forms of transmission and parasite isolates present in domiciliar, peridomiciliar, and sylvatic environments), and the lack of prophylactic therapies and effective chemotherapeutic schemes $[10,16,17]$.

Nifurtimox ([3-methyl-4-(5'-nitrofurfurylideneamine) tetrahydro-4H-1,4-tiazine-1,1-dioxide], Nf) and benznidazole (N-benzyl-2-nitroimidazole acetamide, Bz) were empirically introduced into the clinical therapy regime for CD over four decades ago. Neither drug is ideal because they present variable results depending on the phase of the disease (they are only effective in the acute and recent chronic phases of the infection), the dose and duration of the treatment, patient age, and endemic region in addition to showing undesirable secondary side effects $[18,19]$. Additionally, differences in the susceptibility and natural resistance of different $T$. cruzi isolates to both nitroderivatives have also been reported [20]. It has been suggested that CD must be treated in all its stages, including acute (acquired or congenital), chronic reactivated (under immunosuppressive conditions), indeterminate, and early chronic phases, as determined by the presence of parasitic DNA using PCR analysis [21]. Additionally, although there is still no criterion of cure for symptomatic late chronic cases because most treated individuals show positive serology, recent data suggest the benefits of Bz therapy for chronic patients through the arrest of cardiac damage and a decrease in serology titres [22, 23]. These results reinforce a goal for identifying parasitic targets that is strengthened by the concept that chagasic cardiomyopathy is related to parasitic persistence within the target organs along with an unbalanced host immune response, which could be useful for a new CD therapy [24].

Since the introduction of $\mathrm{Bz}$ and $\mathrm{Nf}$, only allopurinol and a few azoles, such as itraconazole, fluconazole, and ketoconazole, have moved to clinical trials [25-27]. In fact, drug development efforts for $\mathrm{CD}$ are almost exclusively in preclinical research, although phase II studies for the antifungal drug posaconazole and a prodrug of ravuconazole are being planned [28]. In addition, clinical data have demonstrated a positive effect of posaconazole in the therapy of a chronic chagasic patient with systemic lupus erythematosus [29]. However, the high costs of posaconazole may impair its use in CD.

The gap between preclinical studies and clinical trials may be associated with the small amount of investments by pharmaceutical industries due to the low monetary return and to the previous mistaken concept that during the later stages of CD, parasitism is absent [30]. In addition, the lack of standardised protocols and the use of epimastigotes for drug screening may represent significant impairments for the discovery of novel anti-T. cruzi candidates [31]. Based on current knowledge regarding parasite and host physiology, a promising trypanocidal drug would include the following characteristics: (i) high activity against the parasitic forms present in mammalian hosts (intracellular amastigotes and bloodstream trypomastigotes), (ii) high activity against diverse T. cruzi strains for use in different endemic regions, (iii) efficacy against both acute and chronic infections, (iv) oral bioavailability in few doses, (v) low toxicity and improved safety with low potential for genotoxicity and teratogenicity given the potential use in children and women of reproductive age, (vi) low cost and high stability for a long shelf-life in tropical temperatures, (vii) high levels of tissue accumulation and long terminal half-lives, (viii) low risk for cardiotoxicity because the heart is the primary organ affected in chagasic patients, and (ix) low risk for interactions with hepatic cytochrome P450s to avoid drugdrug interactions because many patients use antiarrhythmic drugs and anticoagulants $[28,32]$.

\section{Parasite Targets and Lead Compounds for New Drugs}

Advances in proteomics, biochemistry, and in understanding the biological aspects of T. cruzi infection have allowed for 
the development of new approaches to identify parasitespecific targets and, thus, the design of novel potential drugs $[33,34]$. It has been proposed that a rational therapy for $T$. cruzi should be directed against different parasitic metabolic targets, including ergosterol biosynthesis, trypanothione metabolism, cysteine protease, pyrophosphate metabolism, protein or purine synthesis, and DNA [21, 28, 35-37]. The combination of different drugs with the aim of achieving higher efficiency and lower toxicity is also an interesting therapeutic strategy [38]. Recent studies have demonstrated the successful synergism of posaconazole with amiodarone, an antiarrhythmic drug, against T. cruzi in vitro and in vivo [39]. Another relevant approach is the aetiological therapy of $\mathrm{CD}$ using carrier molecules, such as ruthenium complexes, that bind 14a-demethylase inhibitors [40] or benznidazole [41], improving both solubility and parasite specificity [28]. A recent study has shown the successful use of ruthenium complexes to deliver nitric oxide to T. cruzi-infected cells [42].

Proteomic approaches have been extensively applied for the evaluation of the expression, structure, and function of proteins on a large-scale, including their physiological role, expression regulation, and validity of genome annotations [43]. In trypanosomatids, the control of gene expression is particularly important because all protein-encoding genes are organised in large polycistronic transcription units, producing the RNA that will be processed by trans-splicing. Furthermore, the modulation of protein expression and, consequently, its function is directly related to posttranslational modifications in these protozoa $[44,45]$. Proteomic studies have been performed to evaluate the mechanisms of T. cruzi resistance/susceptibility to drugs [44-46].

In the present review, we summarise in vitro and in vivo results on the efficacy, toxicity, selectivity, and cellular targets of aromatic diamidines and naphthoquinone derivatives, two groups of compounds with promising efficacy against $T$. cruzi. In this framework, morphological techniques, such as light (confocal and fluorescence) and electron (transmission and scanning) microscopy, have been employed. Other cellular (flow cytometry), biochemical (respirometry and fluorimetry), and proteomic (bidimensional electrophoresis and mass spectrometry) approaches have also been employed to identify specific targets in the parasite.

2.1. Aromatic Diamidines and DNA Damages. Diamidines, such as pentamidine, propamidine, and diminazene aceturate, have been successfully used in human and veterinary medicine, and they are the first class of drug extensively employed for early-stage human African trypanosomiasis and for cutaneous leishmaniasis caused by Leishmania guyanensis [47-49]. Their major drawbacks are poor oral bioavailability and severe side effects. To overcome these issues, new dicationic analogues and prodrugs have been synthesised by different medicinal chemistry groups and widely assayed in vitro and in vivo [50]. One of the most promising compounds is an orally effective prodrug of furamidine (DB75) named DB289, which has been in phase III clinical trials for African trypanosomiasis [51]. Unfortunately, recent results at an extended dosage led to the withdrawal of DB289 from human trials due to toxicity issues.

Despite the strong activity of these dicationic compounds against African trypanosomes, few have been assayed as anti-T. cruzi candidates [50]. Our team has recently been working on the potential effect of diamidines and congeners against this parasite using both in vitro and in vivo models to compare analogues with different structures, cationic centres, and effective motifs [19]. Our data have clearly shown the promising activity of some of these compounds, which displayed high therapeutic windows [52-56].

Although DB75 and its N-phenyl-substituted analogue (DB569) display equivalent DNA-binding properties, DB569 exhibited higher in vitro activity against different strains and stages of $T$. cruzi, with $\mathrm{IC}_{50}$ values in the low micromolar range [57]. Due to the characteristic fluorescence of these diamidines, their localisation in DNA-enriched organelles was determined due to strong labelling of the kDNA [58]. Flow cytometry and transmission electron microscopy (TEM) analysis also demonstrated that DB75 and DB569 disturb parasite mitochondria and nuclei, leading to morphological characteristics of programmed cell death, such as higher levels of apoptotic-like parasites observed after the treatment with DB569 $[57,59]$. These findings stimulated further in vivo analysis with this analogue, which showed a reduction in the number of parasites and $\mathrm{CD}^{+} \mathrm{T}$ cells in heart tissues and reversion of electrocardiogram (ECG) alterations in acutely $T$. cruzi-infected mice, leading to an increase in the survival rates [60]. The ECG protection provided by DB569 was also found during the chronic infection of experimental animals, suggesting that the reversion observed in treated animals may be associated with the reduction in cardiac $\mathrm{CD}^{+}$lymphocyte infiltration and parasitism, ultimately contributing to their survival $[59,60]$.

A diarylthiophene diamidine (DB1362) was evaluated against amastigotes and bloodstream trypomastigotes of $T$. cruzi and showed good efficacy in vitro at submicromolar concentrations, inducing low host cytotoxicity. This diamidine presented a dose-dependent trypanocidal effect after incubation in the presence of plasma constituents (mouse blood), exhibiting $\mathrm{IC}_{50}$ values similar to those found in the absence of blood, pointing to its potential prophylactic application in blood banks. TEM and flow cytometry have shown that in bloodstream parasites the most important alterations were in kinetoplast organisation and mitochondrial membrane potential [54]. In an acute T. cruzi experimental mouse model, treatment with two doses of $25 \mathrm{mg} / \mathrm{kg}$ DB1362 (at the onset and at the parasitaemia peak) led to a $40 \%$ decrease in the circulating trypomastigotes and cardiac parasitism (similar levels to $\mathrm{Bz}$ ) and protected against ECG alterations, leading to a $100 \%$ survival rate [54].

Studies on the biological and ultrastructural effect and subcellular localisation of six novel diamidines in $T$. cruzi confirmed their low toxicity towards mammalian cells $\left(\mathrm{LC}_{50}>96 \mu \mathrm{M}\right)$ and demonstrated that small linear molecules (DB1627, DB1646, and DB1670) were not effective. However, the other three diamidines (DB1645, DB1582, and DB1651) were active, with $\mathrm{IC}_{50}$ values between 0.15 and $13.3 \mu \mathrm{M}$ against bloodstream and intracellular amastigotes [61]. 
Several potential transporters of diamidines have been described in other parasites, such as African trypanosomes, Leishmania species and Plasmodium falciparum [62-64]. However, the mechanism of diamidine uptake in T. cruzi is unknown and requires further investigation. The intrinsic fluorescence of some of these compounds allows for monitoring their localisation, as previously reported in studies with African trypanosomes [50, 65, 66]. Some of these diamidines, like DB1582 and DB1651, were localised in parasitic nuclei and kDNA (with higher intensity in kDNA) and within punctate non-DNA-containing cytoplasmic organelles usually localised in the anterior portion of trypomastigotes and near the nuclei and kinetoplasts in amastigotes, which are possibly acidocalcisomes, as previously described for T. brucei [65]. As previously suggested for African trypanosomes, the localisation of these compounds within these acidic organelles could play a role in their mechanism of action and/or act as storage sites $[65,66]$, but additional studies are needed to clarify this matter. Batista et al. [61] demonstrated that these diamidines caused striking alterations in the mitochondria and kinetoplasts of T. cruzi, and some of them also induced disorganisation of microtubules, with the appearance of multiple axoneme structures in trypomastigotes [52,61]. No major alterations have been reported in either subpellicular or flagellar microtubules of $T$. cruzi treated with drugs that target microtubules, such as taxol, colchicines, and vinblastine, possibly due to the high content of acetylated tubulin and/or polyglutamylation of tubulin in these parasites [67]. Because these structures are more resistant to microtubule disrupters in trypanosomatids compared to mammalian cells, they may represent interesting targets for drug development and justify further investigations.

Although the exact mechanism of action of diamidines on T. cruzi and other trypanosomatids has not been clearly demonstrated, it is likely that multiple modes of action may be responsible and that compound uptake represents a fundamental step in their action and selectivity $[50,68]$. One of the long-hypothesised mechanisms of diamidines is related to their selective binding to sequences rich in adenosine and thymine (AT) of kDNA minicircles, leading to kinetoplast destruction and parasite death $[58,69]$. Because the kDNA of trypanosomatids contains high numbers of AT-binding sites in thousands of repeated minicircles, it is possible that these structures represent potential specific targets for diamidines [50]. However, although these compounds are excellent minor groove DNA-binders, this interaction itself cannot fully explain their biological activity. Recent reports have suggested that their association with DNA could represent an initial step followed by topological changes leading to molecular instability and destruction and/or modification of DNA-protein interactions, leading to replication errors, DNA degradation, and parasite death [70]. TEM studies have shown that the organisation of mitochondria and kinetoplasts in $T$. cruzi is highly altered by several diamidines and related compounds, such as arylimidamides (AIAs), at concentrations that do not affect mammalian host cells $[19,51,58]$. AIAs, previously known as reversed amidines, have extraordinary activity against both Leishmania [71-73] and T. cruzi $[52,53,55,56,74]$. They differ from other furan analogues because the amidine is bound to the central aromatic linker via a nitrogen atom rather than a carbon atom [72].

Flow cytometry data have confirmed that diamidines and AIAs target the mitochondria-kinetoplast complex of T. cruzi through interference with the mitochondrial membrane potential $[53,54]$. In vitro screening of novel diamidines against T. cruzi has shown that these compounds localise to a higher extent within the kinetoplast than in the nucleus, and no correlation was found between trypanocidal activity and higher kDNA accumulation $[75,76]$, as previously reported in T. brucei [65]. Other targets for diamidines that also have been proposed include the inhibition of tyrosylDNA phosphodiesterase, topoisomerases, protein kinase A, proteases, and polymerases $[51,77,78]$.

To better understand the mechanism of action of these aromatic compounds, a study of the possible correlation between kDNA-binding properties of 13 amidines with their trypanocidal efficacy against T. cruzi was performed. Four diamidines (DB75, DB569, DB1345, and DB829), eight arylimidamides (DB766, DB749, DB889, DB709, DB613A, DB1831, DB1852, and DB2002), and one guanylhydrazone (DB1080) were assayed using thermal denaturation $\left(T_{m}\right)$ and circular dichroism (CD) studies using both whole T. cruzi purified kDNA and a conserved synthetic parasitic sequence corresponding to the biological activity of each compound [79]. The findings suggest that the strong interaction of amidines with kDNA may not be sufficient to generate and trigger their trypanocidal activity, and other mechanisms of action may be involved and/or associated.

AIAs have potent in vitro dose-dependent activity against T. cruzi, showing superior trypanocidal activity compared to diguanidino cationic groups and other classical diamidines $[52,56]$. Recently, a monoamidine, an arylimidamide, and a guanylhydrazone were evaluated, and the data showed that all compounds exerted, at low micromolar doses, a trypanocidal effect upon both intracellular and bloodstream parasites [74]. However, the potency and selectivity of DB613A, an AIA, towards intracellular parasites (with a selective index >126) corroborated previous results that demonstrated the high promising trypanocidal activity of these compounds.

In vitro and in vivo studies conducted with a novel AIA, DB766, showed its strong trypanocidal activity and excellent selectivity for intracellular amastigotes and trypomastigotes ( $\mathrm{Y}$ strain), the two relevant parasite forms present in mammalian hosts, exhibiting $\mathrm{IC}_{50}$ values of 25 and $60 \mathrm{nM}$, respectively [61]. DB766 also exerted striking effects on a wide panel of different parasite strains, including those naturally resistant to $\mathrm{Nf}$ and $\mathrm{Bz}$, displaying higher activity in vitro than $\mathrm{Bz}$ and gentian violet, which are important requirements for identifying a potential anti- $T$. cruzi agent. It is also important to point that DB766 was active against parasite isolates that circulate in peridomiciliar and sylvatic ecotopes from two different regions in Brazil: (i) the northeast (Jaguaribe Valley, Ceará state) that represents an important area for CD surveillance, where high rates of natural triatomine infection are observed (mostly T. cruzi 
type I lineage) and vectorial control still requires effort to avoid new cases of human transmission, and (ii) the Amazon region that presents an important new epidemiologic challenge due to the increasing reports of human acute cases, mainly by oral contamination as well as by wild triatomine vectorial transmission [61]. Next, as no major acute toxicity was noted with uninfected mice, this AIA was moved to models of acute and chronic experimental T. cruzi infection. DB766 effectively reduced the parasite load in blood and cardiac tissue and presented similar efficacy to $\mathrm{Bz}$ in mouse models of acute and chronic T. cruzi infection (using $\mathrm{Y}$ and Colombiana strains, which are considered modered and highly resistant to $\mathrm{Bz}$ ), using few oral and intraperitoneal doses up to $100 \mathrm{mg} / \mathrm{kg} /$ day given after the establishment of parasite infection. As T. cruzi is an obligatory intracellular parasite and reservoirs of amastigotes can be found in quite distinct organs and tissues, the ability of AIAs (including DB766) to traverse host cell membranes possibly by passive diffusion and or transporters associated with their extensive tissue binding in liver, spleen, and heart [80] makes this class of compounds very attractive for CD treatment. In fact, the pharmacokinetic properties of DB766 are especially relevant since the poor activity of the nitroheterocyclic compounds during the chronic stages of $\mathrm{CD}$ may be related to short half-lives and limited tissue penetration of $\mathrm{Bz}$ and $\mathrm{Nf}$. The efficacy of DB766 upon several strains in vitro and in vivo is a very important finding since this parasite comprises numerous clonal populations with distinct characteristics such as different sensitivity to $\mathrm{Nf}$ and $\mathrm{Bz}$, diverse biological parameters and enzymatic diversity, and strain heterogeneity may also be related to the different clinical manifestations and outcomes in CD. Thus, the broad spectrum of DB766 activity is a desirable characteristic of a novel compound for the treatment of this neglected illness. In acute experimental models of T. cruzi infection, DB766 ameliorated heart alterations, reduced hepatic and heart lesions induced by the infection, and provided $90-100 \%$ protection against mortality. DB766 also presented high in vivo efficacy when given orally at $100 \mathrm{mg} / \mathrm{kg} /$ day, showing similar effect to the Bz-treated group [61]. Interestingly, the oral administration of DB766 (at $100 \mathrm{mg} / \mathrm{kg} /$ day) leads to reduced circulating and cardiac parasitism besides protecting against mortality without causing major side effects. These results suggest that although not being a prodrug, sufficient quantities of DB766 were absorbed from the mouse gastrointestinal tract, effectively delivering this AIA across the gut mucosa, similar to that reported for the AD prodrug DB289. The bulk of these results demonstrate the promising trypanocidal efficacy of DB766, suggesting that AIA may represent a new lead candidate for CD treatment. Interestingly, DB766 produced a clear dose-dependent decrease in parasitaemia in the liver, spleen and bone marrow in two experimental models of L. donovani infection [80]. Additionally, pharmacokinetics, mutagenicity, and toxicity studies revealed that this AIA did not exhibit mutagenicity (AMES test), displayed low acute toxicity, had moderate oral bioavailability, was distributed to different tissues (such as the liver and spleen), presented large areas of distribution, and showed an elimination halflife ranging from one to two days in mice [80].
Six novel aromatic amidinic compounds were tested in vitro to determine activity against the infective and intracellular stages of T. cruzi and evaluate their selectivity and toxicity towards primary cultures of cardiomyocytes [56]. The data demonstrated that all of the aromatic amidines were active against $T$. cruzi in vitro and that the arylimidamide DB1470 was the most effective compound, presenting $\mathrm{IC}_{50}$ values at submicromolar levels and a good selectivity index and maintaining significant trypanocidal activity at $4{ }^{\circ} \mathrm{C}$ in the presence of blood constituents [56]. Interestingly, AIAs, such as DB1470 and DB766, exhibited potent trypanocidal activity against $T$. cruzi in the presence of blood constituents $[52,55]$. This characteristic is highly desirable for new potential trypanocidal agents for use in blood banks in endemic areas. Unfortunately, although transfusional control has led to a decline in the number of new blood bankrelated infections, it is not universally performed. The only trypanocidal agent available for chemical prophylaxis of blood in areas of high endemicity is gentian violet, which is a toxic cationic dye that gives a purple colour to the blood and stains the skin and mucosa of the recipients $[10,81]$. These limitations encourage the search for new compounds that could be used in blood bank prophylaxis; thus, AIAs such as DB766 represent promising agents for further evaluation for this purpose [55]. In summary, the efficacy of diamidines and congeners, like AIAs, against T. cruzi requires further studies to help establish a valuable scheme of therapy for $\mathrm{CD}$.

\subsection{Naphthoquinone Derivatives and Mitochondrial Dysfunc-} tion. Naphthoquinones are compounds present in different families of plants that serve as vital links in the electron transport chains in the metabolic pathway and participate in multiple biological oxidative processes $[82,83]$. They are considered privileged structures in medicinal chemistry due to their biological activities and structural properties [84]. The redox cycling of quinones may be initiated by either a one- or two-electron reduction. The one electron reduction leads to the formation of semiquinones, unstable intermediates that react rapidly with molecular oxygen, generating free radicals. All of these highly reactive oxygen species (ROS) may react directly with DNA or other cellular macromolecules, such as lipids and proteins, leading to cell damage [85]. This reaction results in shunting electrons toward oxygen, an ineffective pathway for reduction equivalents otherwise used for cytochrome P450 reductase-dependent reactions [86-89]. Another alternative is reduction by two electrons, leading to the formation of hydroquinone, mediated by DT-diphorase $[90,91]$. This enzyme reduces toxic, reactive, and unstable quinones, bypassing the creation of toxic intermediates (e.g., a semiquinone radical), and sparing the cell from ROS formation. Whether the two-electron reduction of a quinone leads to detoxification or to activation of oxidative stress depends upon the rate of autoxidation of the formed hydroquinone [86]. If this rate is low under physiological conditions, conjugation may occur before oxidation. As a consequence, the two-electron reduction will lead to detoxification, and an increase in the DTdiphorase activity in tissues would be expected to decrease the toxicity of the quinone. If, however, the hydroquinone 
is rapidly oxidised, only a minor fraction may be conjugated before oxidation occurs, and hydroquinone formation would constitute an activation reaction. As a result, enhanced tissue levels of NQO1 would be expected to increase the toxicity of the quinone [92]. Quinones are oxidants and electrophiles, and the relative contribution of these properties to both their toxic and therapeutic activities is influenced by their chemical structure [93]. Two major mechanisms of quinone cytotoxicity have been proposed: stimulation of oxidative stress and alkylation of cellular nucleophiles, which are the mechanisms of action of encompass a large range of biomolecules [94]. Cellular damage can also occur through the alkylation of crucial proteins and nucleic acids.

In addition to their widespread presence in nature, the great interest in the study and mechanisms of action of compounds with a quinoidal structure is due to their multiple roles in organisms. Several quinonoids isolated from traditional medicinal plants are being investigated for their anticancer properties [95]. The antiprotozoal activities of naphthoquinones have been reported, and several of them have been identified as possible leads for drug development [96-98].

Lapachol is easily isolated from the heartwood of trees of the Bignoniaceae family abundant in tropical rainforests, while both $\alpha$-lapachone and $\beta$-lapachone are present only in small amounts. In Brazil, more than 46 types of such woods, popularly known by the name "ipes" (Tabebuia sp.), have been described. In folk medicine, especially among Indian populations, plants containing naphthoquinones have been employed for the treatment of different diseases, such as cancer [99, 100]. The inner bark of Tabebuia avellanedae, commonly known as "pau d'arco" (lapacho, taheebo), is used as an analgesic, an anti-inflammatory, an antineoplastic, and a diuretic by the local people in the northeastern regions of Brazil [101].

Previous reports have shown that against T. cruzi epimastigotes, $\beta$-lapachone increases the generation of reactive oxygen species through formation of the semiquinone radical, leading to lipid peroxidation and inhibition of nucleic acid and protein synthesis [102-106]. T. cruzi is known to be deficient in reactive oxygen and nitrogen species detoxification and for being especially sensitive to oxidative stress conditions [107]. Its single mitochondrion, containing a branched electron transport chain and a specialised kDNA region [77], is an extraordinary drug target [33]. The ultrastructural injuries observed in $\beta$-lapachonetreated epimastigotes [108] together with the increase in the generation of hydrogen peroxide clearly demonstrates the mitochondrial susceptibility of T. cruzi to naphthoquinones. Unfortunately, no trypanocidal effect was observed in suspensions containing foetal calf serum or rabbit haemoglobin solution, suggesting that $\beta$-lapachone could be inactivated by either reduction in the presence of oxyhaemoglobin or interaction with serum proteins [109].

Due to the easy access to natural sources of quinones from Brazilian flora and the synthetic mechanisms developed by the group of Dr. Pinto (NPPN/UFRJ) exploring the electrophilicity of 1,2-quinoidal carbonyls [110-113], naphthoquinones have been used as starting points for medicinal chemistry studies. Since the 90s, our group has been studying the anti-T. cruzi activity of this class of chemicals [114]. An initial screening was performed on 60 derivatives obtained through the reaction of several naphthoquinones with common reagents from heterocyclic chemistry, leading to 14 oxazolic, 30 imidazolic, and 10 other related heterocyclic compounds [115-119]. Comparing the activity of the original naphthoquinones and their derivatives, we concluded that minor structural features involved with an increase in lipophilicity, such as the furane moiety, the presence of a methoxyl group, and an aliphatic side chain, led to an increase in the effect on T. cruzi. It is possible that a lipophilic character allows better penetration of the compound through the plasma membrane of the parasite. The activity of the synthesised compounds on T. cruzi showed no uniform behaviour and was in some cases higher, lower, or similar to the activity of the original naphthoquinones from which they were obtained. For the naphthooxazoles assayed, there was no correlation between biological activity and the type of the mono-oxygenated ring (pyrane versus furane). As shown for naphthoquinones, a lipophilic characteristic, introduced by this appendage, and the presence of a methoxyl or a phenyl group increased the trypanocidal activity. A characteristic of the synthesised naphthoimidazoles was that most of them had aromatic groups containing electron-releasing or electron-withdrawing groups attached to the imidazole ring, and the most active compounds against $T$. cruzi were obtained from $\beta$-lapachone (see Section 2.3) [115, 119].

Another group of naphthoquinone derivatives was also synthesised and assayed on trypomastigote forms, including $\beta$-lapachone- and nor- $\beta$-lapachone-based 1,2,3triazoles and 3 -arylamino-nor- $\beta$-lapachones $[120,121]$. 1,2,3-Triazoles are an important class of heterocyclic compounds due to their wide range of biological activities. The strategy of molecular hybridisation linking them to naphthoquinones resulted in compounds endowed with redox properties and a trypanocidal profile. The 1,2,3triazole derivatives of nor- $\beta$-lapachone were more active than the original quinone, and the apolar phenyl-substituted derivative (2,2-dimethyl-3-(4-phenyl-1,2,3-triazol-1-yl)2,3-dihydro-naphtho[1,2-b] furan-4,5-dione) was the most active compound $\left(\mathrm{IC}_{50} / 24 \mathrm{~h}=17.3 \pm 2.0 \mu \mathrm{M}\right)$ [120]. Such activity could be due to its higher lipophilic character, which allows better penetration through the parasite's plasma membrane. In addition, the key intermediate azides used for the synthesis of both the $\beta$-lapachone and nor- $\beta$-lapachone series of 1,2,3-triazoles displayed higher activity than $\mathrm{Bz}\left(\mathrm{IC}_{50} / 24 \mathrm{~h}=103.6 \pm 0.6 \mu \mathrm{M}\right)$. In the case of nor- $\beta$-lapachones-3-arylamino-substituted compounds, the insertion of chlorine, bromine, nitro, and methoxy groups into the arylamino ring intensified the trypanocidal activity.

Using nor-lapachol as a starting point, substituted ortho-naphthofuranquinones, a nonsubstituted paranaphthofuranquinone, an oxyrane and an azide were prepared. Using $\alpha$-lapachone as a base, a new nonsubstituted para-naphthofuranquinone was prepared. The most active compounds were three ortho-naphthofuranquinones with trypanocidal activity higher than that of $\mathrm{Bz}[122]$. In another 
set of experiments, three new naphthofuranquinones were synthesised and assayed on T. cruzi. Two of them were obtained by the addition of iodine to C-allyl-lawsone (2hydroxy-3-allyl-naphthoquinone) followed by cyclisation, generating a furan ring; the third was obtained through an acid-catalysed reaction by dissolution of the original quinone in sulphuric acid. These compounds were active on bloodstream trypomastigote and epimastigote forms with $\mathrm{IC}_{50}$ values between $165-640$ and $2.5-25 \mu \mathrm{M}$, respectively [123]. The treatment of infected murine macrophages caused a dose-dependent decrease in the percentage of infection with low toxicity to host mammalian cells (over $100 \mu \mathrm{M}$ ), with $\mathrm{IC}_{50} / 24-96 \mathrm{~h}$ values for intracellular amastigotes between 1.2 and $3.5 \mu \mathrm{M}$ [124]. An ultrastructural analysis of treated epimastigotes and trypomastigotes indicated a potent effect of the three naphthofuranquinones on parasitic mitochondria, which appeared drastically swollen and with a washed-out matrix profile. Fluorescenceactivated cell sorting analysis of rhodamine-123-stained T. cruzi showed that these naphthofuranquinones caused a potent dose-dependent collapse of the mitochondrial membrane potential $\left(\Delta \Psi_{m}\right)$, especially in epimastigote forms. Such a collapse represented a $30-60 \%$ decrease in the parasitic $\Delta \Psi_{m}$. These compounds also specifically decreased mitochondrial complex I-III activities parallel to a reduction in succinate-induced oxygen consumption between 64$75 \%$ in epimastigotes and $72-92 \%$ in trypomastigotes. Mitochondrial hydrogen peroxide formation was also increased 1.3-4.5-fold in epimastigotes after treatment with naphthofuranquinones. Our results indicated that the trypanocidal action of these quinones was associated with mitochondrial dysfunction, leading to increased reactive oxygen species generation and parasitic death [124]. The easy synthetic route of these compounds in the laboratory opens the possibility of large-scale production with high yields for assays in experimental mouse models.

2.3. Naphthoimidazoles and Putative Targets. Among the different classes of naphthoquinone derivatives screened against T. cruzi (see Section 2.2), the most active derivatives against bloodstream trypomastigotes were three naphthoimidazoles derived from $\beta$-lapachone with the aromatic moieties phenyl (N1), 3-indolyl (N2), and methyl-p-phenyl (N3), which were selected for further studies $[84,85]$. They were also active against intracellular amastigotes and epimastigotes (Table 1) and showed toxicity to the host cell in concentrations greater than $100 \mu \mathrm{M}$. The most susceptible form of the parasite was the intracellular amastigotes, with an $\mathrm{IC}_{50} / 24 \mathrm{~h}$ between 6.5 and $9.0 \mu \mathrm{M}[125,126]$. The highest activity against bloodstream forms was observed for $\mathrm{N} 2$, with $\mathrm{IC}_{50} / 24 \mathrm{~h}$ values of $12.3 \pm 1.2$ and $61.6 \pm 3.6 \mu \mathrm{M}$ for $0 \%$ and $100 \%$ blood, respectively. In epimastigotes, N3 was the most effective, with $\mathrm{IC}_{50} / 24 \mathrm{~h}$ values of $30.7 \pm 3.6 \mu \mathrm{M}$. All three compounds also blocked the cell cycle (up to $96 \%$ inhibition of DNA duplication), inhibited succinate cytochrome $\mathrm{c}$ reductase (16-42\%) and metacyclogenesis $\left(\mathrm{IC}_{50} / 96 \mathrm{~h}\right.$ values between $0.35-0.66 \mu \mathrm{M}$ ) and induced extensive morphological damage to the mitochondria, Golgi complex and reservosomes. In treated trypomastigotes, an altered kinetoplast network, mitochondrial swelling, plasma membrane blebbing and DNA fragmentation were found $[125,126]$. DNA fragmentation was also evaluated using total DNA electrophoresis and flow cytometry techniques and showed a maximum of $75 \%$ TUNEL+ trypomastigotes after treatment with the naphthoimidazoles.

An investigation into their mode of action led to the characterisation of mitochondria, reservosomes, and DNA as their main targets and stimulated further studies about death pathways. Ultrastructural analysis revealed both autophagic (autophagosomes) and apoptotic-like (membrane blebbing) phenotypes. In epimastigotes and trypomastigotes, the naphthoimidazoles induced the formation of concentric membranes, autophagosomes with a loss of matrix electron density, and endoplasmic reticulum profiles surrounding different structures [127]. Apoptosis-like features, such as the release of mitochondrial cytochrome $\mathrm{c}$ to the cytosol, has also been detected in N3-treated parasites. Flow cytometry analysis showed a small increase in phosphatidylserine exposure in N2-treated trypomastigotes and a large increase in the percentage of necrosis caused by N1 and N2. These death phenotypes were not detected in treated epimastigotes. A strong increase in the labelling of monodansyl cadaverine (a well-known autophagic marker) was observed up to 45 and $71 \%$ in treated trypomastigotes and epimastigotes, respectively. The inhibition of the trypanocidal action of the three naphthoimidazoles by wortmannin or 3-methyladenine together with the overexpression of ATG3, ATG4, ATG7, and ATG8 genes in treated epimastigotes and the ultrastructural evidence pointed to autophagy as the predominant phenotype induced by these compounds [127, 128].

To assess the mechanism of action of the naphthoimidazoles N1, N2, and N3, treated epimastigotes were submitted to two-dimensional gel electrophoresis (2-DE) and mass spectrometry to monitor changes in the protein patterns of different important pathways in T. cruzi. Results showed that 9 of the 30 proteins altered were mitochondrial, reinforcing previous morphological and biochemical studies that showed this organelle as the main target of these drugs $[125,126]$. Treatment with the compounds led to an upregulation of three proteins: heat-shock protein 85 , enolase 1 and trypanothione synthetase (Table 2). The overmodulation of the trypanothione pathway strongly suggests that increased scavenging is necessary due to the increased thiol content in treated parasites, as previously described for trypanosomatids [129].

The downregulation of 26 proteins was observed: 7 in N1, 14 in N2, and 15 in N3. Table 2 summarises all modulated proteins after treatment. A strong decrease $(20-80 \%)$ in protein levels was detected after treatment with the three naphthoimidazoles. Energy metabolism is an important target of these compounds. The expression of enzymes, such as enolase, pyruvate dehydrogenase, and cytochrome $c$ oxidase, were altered in treated epimastigotes. Interference with ATP generation occurred in different stages of the pathway, including glycolysis, the citric acid cycle, and the mitochondrial electron transport chain. The main structural target of naphthoimidazoles was microtubules. A remarkable 
TABLE 1: $\mathrm{IC}_{50}$ values/1 d $(\mu \mathrm{M})$ for the effect of N1, N2, and N3 against T. cruzi $^{\text {a }}$.

\begin{tabular}{lccccc}
\hline & \multicolumn{2}{c}{ Trypomastigotes } & \multirow{2}{*}{ Epimastigotes } & \multicolumn{2}{c}{ Amastigotes } \\
& $0 \%$ blood & $100 \%$ blood & & Extracellular $^{\mathrm{b}}$ & Intracellular $^{\mathrm{c}}$ \\
\hline N1 & $35.8 \pm 1.2^{\mathrm{d}}$ & $62.1 \pm 3.0$ & $82.8 \pm 7.4$ & $13.4 \pm 1.1$ & $9.0 \pm 2.9$ \\
N2 & $12.3 \pm 1.2$ & $61.6 \pm 3.6$ & $36.0 \pm 1.9$ & $12.4 \pm 1.9$ & $6.5 \pm 1.0$ \\
N3 & $28.2 \pm 0.9$ & $68.3 \pm 7.3$ & $30.7 \pm 3.6$ & $9.7 \pm 0.2$ & $7.2 \pm 0.2$ \\
\hline
\end{tabular}

${ }^{a}$ References [123, 124].

${ }^{\mathrm{b}}$ Tissue-cultured derived amastigotes.

${ }^{\mathrm{c}}$ Number of amastigotes/100 peritoneal macrophages.

$\mathrm{d}_{\mathrm{Mean}} \pm \mathrm{SD}$ of at least 3 independent experiments.

TABLE 2: Modulated proteins in naphthoimidazoles-treated epimastigotes ${ }^{\mathrm{a}}$.

\begin{tabular}{|c|c|c|}
\hline Protein description & Expression status & Treatment \\
\hline Trypanothione synthetase & upregulated & $\mathrm{N} 1, \mathrm{~N} 2, \mathrm{~N} 3$ \\
\hline Mitochondrial heat shock & downregulated & $\mathrm{N} 1$ \\
\hline Heat shock protein 60 & downregulated & N2 \\
\hline Elogation factor $1-\alpha$ & downregulated & N1 \\
\hline Enolase 1 & upregulated & N3 \\
\hline Glutamamyl carboxypeptidase & downregulated & N1 \\
\hline Heat shock protein 85 & upregulated/downregulated & $\mathrm{N} 1, \mathrm{~N} 2, \mathrm{~N} 3$ \\
\hline Tyrosine aminotransferase & downregulated & N3 \\
\hline Cytochrome C oxidase subunit IV & downregulated & N2 \\
\hline Activated PKC receptor & downregulated & N3 \\
\hline Hypothetical protein & downregulated & $\mathrm{N} 2$ \\
\hline$\beta$-tubulin & downregulated & $\mathrm{N} 1, \mathrm{~N} 2$ \\
\hline Pyruvate dehydrogenase E1 $\beta$ subunit & downregulated & N3 \\
\hline Sterol 24-C-methyltransferases & downregulated & $\mathrm{N} 2, \mathrm{~N} 3$ \\
\hline Elongation factor $1-\beta$ & downregulated & $\mathrm{N} 2$ \\
\hline Proteosome $\alpha 7$ subunit & downregulated & N1 \\
\hline Peroxiredoxin & downregulated & N2 \\
\hline Hypothetical protein & downregulated & N1 \\
\hline IgE-dependent histamine-releasing factor & downregulated & N3 \\
\hline Elongation factor 2 & downregulated & N2 \\
\hline Dehydrogenase & downregulated & N3 \\
\hline Cystathionine $\beta$-synthase 6 & downregulated & N2 \\
\hline$\alpha$-tubulin & downregulated & N3 \\
\hline
\end{tabular}

${ }^{a}$ Reference [128].

decrease in the $\alpha$ - and $\beta$-tubulin content was detected in epimastigotes treated with the three compounds. Interestingly, previous ultrastructural data showed no damage to subpellicular and flagellar conformations after treatment $[125,126]$. ELISA showed a decrease in tyrosinated tubulin content, suggesting interference with intracellular vesicle traffic and/or mitotic spindle formation, data reinforced by the blockage of mitosis in naphthoimidazole-treated epimastigotes $[126,130]$. Amino acid metabolism was one of the most important targets of the naphthoimidazoles. The levels of tyrosine aminotransferase, elongation factors and different heat-shock proteins were affected by N1, N2, and $\mathrm{N} 3$, leading to a decrease in the amino acid synthesis and, consequently, an imbalance in proteins important for cell survival. N2 and N3 also arrested the latter steps of sterol biosynthesis through the downregulation of sterol 24-Cmethyltransferase (Table 2). The partial impairment of this pathway could lead to alterations in the lipid composition, with a loss of membrane fluidity. Proteomic and ultrastructural data showed no evidence of necrosis or apoptosis-like cell death in treated parasites $[127,130]$. A further detailed study on metabolic interactions is crucial to further elucidate the mechanisms through which naphthoimidazoles act.

\section{Concluding Remarks}

Despite the drawbacks found during the therapy of chagasic patients with $\mathrm{Bz}$ and $\mathrm{Nf}$, in the last decades, only a few compounds have moved to clinical trials, possibly due to the low investments allocated to this area and the lack of standardised protocols for drug screening [31]. As previously noted, "the more leads/approaches that progress to investigational drug candidates, the better chance that new treatments for this often fatal infection will be available to patients in the 
near future" [131]. Thus, the recent implementation of highthroughput compound screening against T. cruzi will allow for the rapid evaluation of several thousands of compounds per month against intracellular amastigotes, which represent an important tool that may yield the identification of novel promising compounds that can move to clinical trials [28].

However, these promising trypanocidal candidates will need more complete pharmacological and safety test analyses to be considered for clinical trials. However, consistent care must be provided through the adoption of a biopsychosocial model, considering patient therapy in the context of biological, psychological, and social factors, and economic difficulties, which can compromise quality of life $[132,133]$. Finally, another important limitation related to moving new compounds towards clinical trials is the absence of feasible markers to monitor the progression of the chronic disease and affordable, efficient, and accessible diagnostic tests. Thus, the development of new drugs for most parasitic diseases requires a multidisciplinary approach involving diverse research areas, such as molecular and cellular biology, chemistry and biochemistry, pharmacology, and toxicology, to provide new insights related to the development and discovery of more selective compounds that could be used for Chagas disease therapy.

As concluded by Abad-Franch et al. [8] , improved specific chemotherapy, including more practical formulations (e.g., paediatric) or combinations of existing drugs, and a better understanding of pathogenesis as well as the relative contribution of the parasite and host genetic makeup are clearly needed. New strategies for drug design have been improved by the recent results in T. cruzi biochemistry, allowing for better elucidation of the effects of trypanocidal agents.

\section{Acknowledgments}

The present paper was supported by grants from Fundação Carlos Chagas Filho de Amparo a Pesquisa do Estado do Rio de Janeiro, Pronex/Faperj, CNE/Faaperj, PensaRio/Faperj, Conselho Nacional de Desenvolvimento Científico e Tecnológico (CNPq), and Fundação Oswaldo Cruz (Fiocruz).

\section{References}

[1] M. O. C. Rocha, M. M. Teixeira, and A. L. Ribeiro, "An update on the management of Chagas cardiomyopathy," Expert Review of Anti-Infective Therapy, vol. 5, no. 4, pp. 727743, 2007.

[2] A. Rassi Jr., A. Rassi, and J. A. Marin-Neto, "Chagas disease," The Lancet, vol. 375, no. 9723, pp. 1388-1402, 2010.

[3] B. L. Herwaldt, "Laboratory-acquired parasitic infections from accidental exposures," Clinical Microbiology Reviews, vol. 14, no. 4, pp. 659-688, 2001.

[4] J. D. Altclas, L. Barcan, C. Nagel, R. Lattes, and A. Riarte, "Organ transplantation and Chagas disease," Journal of the American Medical Association, vol. 299, no. 10, pp. 34-35, 2008.

[5] M. Steindel, L. Kramer Pacheco, D. Scholl et al., "Characterization of Trypanosoma cruzi isolated from humans, vectors, and animal reservoirs following an outbreak of acute human
Chagas disease in Santa Catarina State, Brazil," Diagnostic Microbiology and Infectious Disease, vol. 60, no. 1, pp. 25-32, 2008.

[6] G. A. Schmunis, "Epidemiology of Chagas disease in nonendemic countries: the role of international migration," Memórias do Instituto Oswaldo Cruz, vol. 102, supplement 1, pp. 75-85, 2007.

[7] J. C. P. Dias, A. Prata, and D. Correia, "Problems and perspectives for Chagas disease control: in search of a realistic analysis," Revista da Sociedade Brasileira de Medicina Tropical, vol. 41, no. 2, pp. 193-196, 2008.

[8] F. Abad-Franch, W. S. Santos, and C. J. Schofield, "Research needs for Chagas disease prevention," Acta Tropica, vol. 115, no. 1-2, pp. 44-54, 2010.

[9] J. R. Coura and J. Borges-Pereira, "Chagas disease: 100 years after its discovery. A systemic review," Acta Tropica, vol. 115, no. 1-2, pp. 5-13, 2010.

[10] J. Clayton, "Chagas disease: pushing through the pipeline," Nature, vol. 465, no. 7301, pp. S12-S15, 2010.

[11] A. M. B. Bilate and E. Cunha-Neto, "Chagas disease cardiomyopathy: current concepts of an old disease," Revista do Instituto de Medicina Tropical de São Paulo, vol. 50, no. 2, pp. 67-74, 2008.

[12] C. Junqueira, B. Caetano, D. C. Bartholomeu et al., "The endless race between Trypanosoma cruzi and host immunity: iessons for and beyond Chagas disease," Expert Reviews in Molecular Medicine, vol. 12, p. e29, 2010.

[13] M. D. L. Higuchi, L. A. Benvenuti, M. M. Reis, and M. Metzger, "Pathophysiology of the heart in Chagas' disease: current status and new developments," Cardiovascular Research, vol. 60, no. 1, pp. 96-107, 2003.

[14] A. P. Marino, A. A. Silva, P. V. Santos et al., "CC-chemokine receptors: a potential therapeutic target for Trypanosoma cruzi-elicited myocarditis," Memórias do Instituto Oswaldo Cruz, vol. 100, no. 1, pp. 93-96, 2005.

[15] C. Chagas, "Nova tripanosomíase humana-estudos sobre a morfologia e o ciclo evolutivo de Schizotrypanum cruzi gen. nov. sp. nov., agente etiológico de nova entidade mórbida do homem," Memórias do Instituto Oswaldo Cruz, vol. 1, pp. 159-218, 1909.

[16] J. C. P. Dias, "Globalization, inequity and Chagas disease," Cadernos de Saúde Pública, vol. 23, supplement 1, pp. S13S22, 2007.

[17] J. R. Coura, "Chagas disease: what is known and what is needed-a background article," Memórias do Instituto Oswaldo Cruz, vol. 102, supplement 1, pp. 113-122, 2007.

[18] J. R. Coura and S. L. De Castro, "A critical review on chagas disease chemotherapy," Memórias do Instituto Oswaldo Cruz, vol. 97, no. 1, pp. 3-24, 2002.

[19] M. N. C. Soeiro, A. P. Dantas, A. Daliry et al., "Experimental chemotherapy for Chagas disease: 15 years of research contributions from in vivo and in vitro studies," Memórias do Instituto Oswaldo Cruz, vol. 104, supplement 1, pp. 301-310, 2009.

[20] L. S. Filardi and Z. Brener, "Susceptibility and natural resistance of Trypanosoma cruzi strains to drugs used clinically in Chagas disease," Transactions of the Royal Society of Tropical Medicine and Hygiene, vol. 81, no. 5, pp. 755-759, 1987.

[21] W. Apt, "Current and developing therapeutic agents in the treatment of Chagas disease," Drug Design, Development and Therapy, vol. 4, pp. 243-253, 2010.

[22] R. Viotti, C. Vigliano, B. Lococo et al., "Long-term cardiac outcomes of treating chronic chagas disease with benznidazole versus no treatment: a nonrandomized trial," Annals of Internal Medicine, vol. 144, no. 10, pp. 724-734, 2006. 
[23] R. Viotti and C. Vigliano, "Etiological treatment of chronic Chagas disease: neglected 'evidence' by evidence-based medicine," Expert Review of Anti-Infective Therapy, vol. 5, no. 4, pp. 717-726, 2007.

[24] J. A. Marin-Neto, A. Rassi Jr., C. A. Morillo et al., "Rationale and design of a randomized placebo-controlled trial assessing the effects of etiologic treatment in Chagas' cardiomyopathy: the BENznidazole evaluation for interrupting Trypanosomiasis (BENEFIT)," American Heart Journal, vol. 156, no. 1, pp. 37-43, 2008.

[25] Z. Brener, J. R. Cançado, L. M. Galvão et al., "An experimental and clinical assay with ketoconazole in the treatment of Chagas disease," Memórias do Instituto Oswaldo Cruz, vol. 88, no. 1, pp. 149-153, 1993.

[26] A. Solari, H. Saavedra, C. Sepulveda et al., "Successful treatment of Trypanosoma cruzi encephalitis in a patient with hemophilia and AIDS," Clinical Infectious Diseases, vol. 16, no. 2, pp. 255-259, 1993.

[27] W. Apt, A. Arribada, I. Zulantay et al., "Itraconazole or allopurinol in the treatment of chronic American trypanosomiasis: the results of clinical and parasitological examinations 11 years post-treatment," Annals of Tropical Medicine and Parasitology, vol. 99, no. 8, pp. 733-741, 2005.

[28] F. S. Buckner and N. Navabi, "Advances in Chagas disease drug development: 2009-2010," Current Opinion in Infectious Diseases, vol. 23, no. 6, pp. 609-616, 2010.

[29] M. J. Pinazo, G. Espinosa, M. Gállego, P. L. López-Chejade, J. A. Urbina, and J. Gascón, "Case report: successful treatment with posaconazole of a patient with chronic Chagas disease and systemic lupus erythematosus," American Journal of Tropical Medicine and Hygiene, vol. 82, no. 4, pp. 583-587, 2010.

[30] M. N. C. Soeiro and S. L. De Castro, "Novel promising synthetic trypanocidal agents against Trypanosoma cruzi: in vitro and in vivo studies," Open Medicinal Chemistry Journal. In press.

[31] A. J. Romanha, S. L. de Castro, M. N. C. Soeiro et al., "In vitro and in vivo experimental models for drug screening and development for Chagas disease," Memórias do Instituto Oswaldo Cruz, vol. 105, no. 2, pp. 233-238, 2010.

[32] S. Nwaka and A. Hudson, "Innovative lead discovery strategies for tropical diseases," Nature Reviews Drug Discovery, vol. 5, no. 11, pp. 941-955, 2006.

[33] M. N. C. Soeiro and S. L. De Castro, "Trypanosoma cruzi targets for new chemotherapeutic approaches," Expert Opinion on Therapeutic Targets, vol. 13, no. 1, pp. 105-121, 2009.

[34] J. A. Urbina, "Specific chemotherapy of Chagas disease: relevance, current limitations and new approaches," Acta Tropica, vol. 115, no. 1-2, pp. 55-68, 2010.

[35] G. Rivera, V. Bocanegra-García, C. Ordaz-Pichardo, B. Nogueda-Torres, and A. Monge, "New therapeutic targets for drug design against Trypanosoma cruzi, advances and perspectives," Current Medicinal Chemistry, vol. 16, no. 25, pp. 3286-3293, 2009.

[36] D. R. M. Moreira, A. C. L. Leite, R. R. dos Santos, and M. B. P. Soares, "Approaches for the development of new antiTrypanosoma cruzi agents," Current Drug Targets, vol. 10, no. 3, pp. 212-231, 2009.

[37] F. Sánchez-Sancho, N. E. Campillo, and J. A. Páez, "Chagas disease: progress and new perspectives," Current Medicinal Chemistry, vol. 17, no. 5, pp. 423-452, 2010.

[38] J. R. Coura, "Present situation and new strategies for chagas disease chemotherapy-a proposal," Memórias do Instituto Oswaldo Cruz, vol. 104, no. 4, pp. 549-554, 2009.
[39] G. Benaim, J. M. Sanders, Y. Garcia-Marchán et al., "Amiodarone has intrinsic anti-Trypanosoma cruzi activity and acts synergistically with posaconazole," Journal of Medicinal Chemistry, vol. 49, no. 3, pp. 892-899, 2006.

[40] R. A. Sánchez-Delgado and A. Anzelloti, "Metal complexes as chemotherapeutic agents against tropical diseases: trypanosomiasis, malaria and leishmaniasis," Mini-Reviews in Medicinal Chemistry, vol. 4, no. 1, pp. 23-30, 2004.

[41] J. J. N. Silva, W. R. Pavanelli, F. R. Gutierrez et al., "Complexation of the anti-Trypanosoma cruzi drug benznidazole improves solubility and efficacy," Journal of Medicinal Chemistry, vol. 51, no. 14, pp. 4104-4114, 2008.

[42] P. M. Guedes, F. S. Oliveira, F. R. Gutierrez et al., "Nitric oxide donor trans-[ $\mathrm{RuCl}([15]$ aneN $) \mathrm{NO}]$ as a possible therapeutic approach for Chagas' disease," British Journal of Pharmacology, vol. 160, no. 2, pp. 270-282, 2010.

[43] M. Ferella, D. Nilsson, H. Darban et al., "Proteomics in Trypanosoma cruzi- Localization of novel proteins to various organelles," Proteomics, vol. 8, no. 13, pp. 2735-2749, 2008.

[44] A. Parodi-Talice, R. Durán, N. Arrambide et al., "Proteome analysis of the causative agent of Chagas disease: Trypanosoma cruzi," International Journal for Parasitology, vol. 34, no. 8, pp. 881-886, 2004.

[45] H. M. Andrade, S. M. F. Murta, A. Chapeaurouge, J. Perales, P. Nirdé, and A. J. Romanha, "Proteomic analysis of Trypanosoma cruzi resistance to benznidazole," Journal of Proteome Research, vol. 7, no. 6, pp. 2357-2367, 2008.

[46] J. A. Atwood, D. B. Weatherly, T. A. Minning et al., "Microbiology: the Trypanosoma cruzi proteome," Science, vol. 309, no. 5733, pp. 473-476, 2005.

[47] P. L. Olliaro, P. J. Guerin, S. Gerstl, A. A. Haaskjold, J. A. Rottingen, and S. Sundar, "Treatment options for visceral leishmaniasis: a systematic review of clinical studies done in India, 1980-2004," Lancet Infectious Diseases, vol. 5, no. 12, pp. 763-774, 2005.

[48] J. Blum, P. Desjeux, E. Schwartz, B. Beck, and C. Hatz, "Treatment of cutaneous leishmaniasis among travellers," Journal of Antimicrobial Chemotherapy, vol. 53, no. 2, pp. 158-166, 2004.

[49] K. Werbovetz, "Diamidines as antitrypanosomal, antileishmanial and antimalarial agents," Current Opinion in Investigational Drugs, vol. 7, no. 2, pp. 147-157, 2006.

[50] W. D. Wilson, F. A. Tanious, A. Mathis, D. Tevis, J. E. Hall, and D. W. Boykin, "Antiparasitic compounds that target DNA," Biochimie, vol. 90, no. 7, pp. 999-1014, 2008.

[51] M. N. Soeiro, S. L. de Castro, E. M. de Souza, D. G. Batista, C. F. Silva, and D. W. Boykin, "Diamidine activity against trypanosomes: the state of the art," Current Molecular Pharmacology, vol. 1, no. 2, pp. 151-161, 2008.

[52] C. F. Silva, M. M. Batista, R. A. Mota et al., "Activity of "reversed" diamidines against Trypanosoma cruzi in vitro," Biochemical Pharmacology, vol. 73, no. 12, pp. 1939-1946, 2007.

[53] C. F. Silva, M. B. Meuser, E. M. De Souza et al., "Cellular effects of reversed amidines on Trypanosoma cruzi," Antimicrobial Agents and Chemotherapy, vol. 51, no. 11, pp. 38033809, 2007.

[54] C. F. Da Silva, M. M. Batista, D. D. G. J. Batista et al., "In vitro and in vivo studies of the trypanocidal activity of a diarylthiophene diamidine against Trypanosoma cruzi," Antimicrobial Agents and Chemotherapy, vol. 52, no. 9, pp. 3307-3314, 2008.

[55] D. G. J. Batista, M. G. O. Pacheco, A. Kumar et al., "Biological, ultrastructural effect and subcellular localization of aromatic diamidines in Trypanosoma cruzi," Parasitology, vol. 137, no. 2, pp. 251-259, 2010. 
[56] E. M. De Souza, P. B. da Silva, A. S. Nefertiti et al., "Trypanocidal activity and selectivity in vitro of aromatic amidine compounds upon bloodstream and intracellular forms of Trypanosoma cruzi," Experimental Parasitology, vol. 127, no. 2, pp. 429-435, 2011.

[57] E. M. De Souza, A. Lansiaux, C. Bailly et al., "Phenyl substitution of furamidine markedly potentiates its antiparasitic activity against Trypanosoma cruzi and Leishmania amazonensis," Biochemical Pharmacology, vol. 68, no. 4, pp. 593-600, 2004.

[58] M. N. C. Soeiro, E. M. De Souza, C. E. Stephens, and D. W. Boykin, "Aromatic diamidines as antiparasitic agents," Expert Opinion on Investigational Drugs, vol. 14, no. 8, pp. 957-972, 2005.

[59] E. M. de Souza, G. M. Oliveira, D. W. Boykin, A. Kumar, Q. Hu, and M. D. N. Soeiro, "Trypanocidal activity of the phenyl-substituted analogue of furamidine DB569 against Trypanosoma cruzi infection in vivo," Journal of Antimicrobial Chemotherapy, vol. 58, no. 3, pp. 610-614, 2006.

[60] E. M. De Souza, G. M. Oliveira, and M. N. C. Soeiro, "Electrocardiographic findings in acutely and chronically Trypansoma cruzi-infected mice treated by a phenyl-substituted analogue of furamidine DB569," Drug Targets Insights, vol. 2, no. 2, pp. 61-69, 2007.

[61] D. D. G. J. Batista, M. M. Batista, G. M. De Oliveira et al., "Arylimidamide DB766, a potential chemotherapeutic candidate for Chagas' disease treatment," Antimicrobial Agents and Chemotherapy, vol. 54, no. 7, pp. 2940-2952, 2010.

[62] N. S. Carter, B. J. Berger, and A. H. Fairlamb, "Uptake of diamidine drugs by the P2 nucleoside transporter in melarsen- sensitive and -resistant Trypanosoma brucei brucei," Journal of Biological Chemistry, vol. 270, no. 47, pp. 28153-28157, 1995.

[63] M. P. Barrett, R. J. S. Burchmore, A. Stich et al., "The trypanosomiases," Lancet, vol. 362, no. 9394, pp. 1469-1480, 2003.

[64] P. G. Bray, M. P. Barrett, S. A. Ward, and H. P. De Koning, "Pentamidine uptake and resistance in pathogenic protozoa: past, present and future," Trends in Parasitology, vol. 19, no. 5, pp. 232-239, 2003.

[65] A. M. Mathis, J. L. Holman, L. M. Sturk et al., "Accumulation and intracellular distribution of antitrypanosomal diamidine compounds DB75 and DB820 in African trypanosomes," Antimicrobial Agents and Chemotherapy, vol. 50, no. 6, pp. 2185-2191, 2006.

[66] A. M. Mathis, A. S. Bridges, M. A. Ismail et al., "Diphenyl furans and aza analogs: effects of structural modification on in vitro activity, DNA binding, and accumulation and distribution in trypanosomes," Antimicrobial Agents and Chemotherapy, vol. 51, no. 8, pp. 2801-2810, 2007.

[67] T. Souto-Padron, N. L. Cunha e Silva, and W. de Souza, "Acetylated alpha-tubulin in Trypanosoma cruzi: immunocytochemical localization," Memórias do Instituto Oswaldo Cruz, vol. 88, no. 4, pp. 517-528, 1993.

[68] H. P. De Koning, "Uptake of pentamidine in Trypanosoma brucei brucei is mediated by three distinct transporters: implications for cross-resistance with arsenicals," Molecular Pharmacology, vol. 59, no. 3, pp. 586-592, 2001.

[69] W. D. Wilson, B. Nguyen, F. A. Tanious et al., "Dications that target the DNA minor groove: compound design and preparation, DNA interactions, cellular distribution and biological activity," Current Medicinal Chemistry and AntiCancer Agents, vol. 5, no. 4, pp. 389-408, 2005.

[70] G. Singh and C. S. Dey, "Induction of apoptosis-like cell death by pentamidine and doxorubicin through differential inhibition of topoisomerase II in arsenite-resistant Leishmania donovani," Acta Tropica, vol. 103, no. 3, pp. 172-185, 2007.

[71] A. C. Rosypal, J. E. Hall, S. Bakunova et al., "In vitro activity of dicationic compounds against a North American foxhound isolate of Leishmania infantum," Veterinary Parasitology, vol. 145, no. 3-4, pp. 207-216, 2007.

[72] A. C. Rosypal, K. A. Werbovetz, M. Salem et al., "Inhibition by dications of in vitro growth of Leishmania major and Leishmania tropica: causative agents of old world cutaneous leishmaniasis," Journal of Parasitology, vol. 94, no. 3, pp. 743749, 2008.

[73] C. E. Stephens, R. Brun, M. M. Salem et al., "The activity of diguanidino and 'reversed' diamidino 2,5-diarylfurans versus Trypanosoma cruzi and Leishmania donovani," Bioorganic and Medicinal Chemistry Letters, vol. 13, no. 12, pp. 2065-2069, 2003.

[74] M. G. D. O. Pacheco, C. F. D. Silva, E. M. D. Souza et al., "Trypanosoma cruzi: activity of heterocyclic cationic molecules in vitro," Experimental Parasitology, vol. 123, no. 1, pp. 73-80, 2009.

[75] A. Daliry, P. B. Da Silva, C. F. Da Silva et al., "In vitro analyses of the effect of aromatic diamidines upon Trypanosoma cruzi," Journal of Antimicrobial Chemotherapy, vol. 64, no. 4, pp. 747-750, 2009.

[76] A. Daliry, C. F. da Silva, P. B. da Silva, M. M. Batista, R. R. Tidwell, and M. N. C. Soeiro, "The biological in vitro effect and selectivity of aromatic dicationic compounds on Trypanosoma cruzi," Memórias do Instituto Oswaldo Cruz, vol. 105, no. 3, pp. 239-245, 2010.

[77] T. A. Shapiro and P. T. Englund, "The structure and replication of kinetoplast DNA," Annual Review of Microbiology, vol. 49, pp. 117-143, 1995.

[78] C. C. Dykstra, D. R. McClernon, L. P. Elwell, and R. R. Tidwell, "Selective inhibition of topoisomerases from Pneumocystis carinii compared with that of topoisomerases from mammalian cells," Antimicrobial Agents and Chemotherapy, vol. 38, no. 9, pp. 1890-1898, 1994.

[79] A. Daliry, M. Munde, M. Q. Pires et al., "The trypanocidal activity of amidine compounds does not correlated with their binding affinity to parasite KDNA," submitted to publication.

[80] M. Z. Wang, X. Zhu, A. Srivastava et al., "Novel arylimidamides for treatment of visceral leishmaniasis," Antimicrobial Agents and Chemotherapy, vol. 54, no. 6, pp. 2507-2516, 2010.

[81] E. Chiari, A. B. Oliveira, M. A. F. Prado, R. J. Alves, L. M. C. Galvão, and F. G. Araujo, "Potential use of WR6026 as prophylaxis against transfusion-transmitted American trypanosomiasis," Antimicrobial Agents and Chemotherapy, vol. 40, supplement 3, pp. 613-615, 1996.

[82] G. Powis, "Metabolism and reactions of quinoid anticancer agents," Pharmacology and Therapeutics, vol. 35, no. 1-2, pp. 57-162, 1987.

[83] P. J. O’Brien, “Molecular mechanisms of quinone cytotoxicity," Chemico-Biological Interactions, vol. 80, no. 1, pp. 1-41, 1991.

[84] L. Costantino and D. Barlocco, "Privileged structures as leads in medicinal chemistry," Current Medicinal Chemistry, vol. 13, no. 1, pp. 65-85, 2006.

[85] A. V. Pinto, R. F. S. Menna-Barreto, and S. L. De Castro, "Naphthoquinones isolated from Tabebuia: a review about the synthesis of heterocyclic derivatives, screeening against Trypanosoma cruzi and correlation structure-trypanocidal activity," in Recent Progress in Medicinal Plants, J. N. Govil, Ed., vol. 16, pp. 112-127, Studium Press, Houston, Tex, USA, 2006. 
[86] S. F. Villamil, A. O. M. Stoppani, and M. Dubin, "Redox cycling of $\beta$-lapachone and structural analogues in microsomal and cytosol liver preparations," Methods in Enzymology, vol. 378, pp. 67-87, 2004.

[87] A. Brunmark and E. Cadenas, "Redox and addition chemistry of quinoid compounds and its biological implications," Free Radical Biology and Medicine, vol. 7, no. 4, pp. 435-477, 1989.

[88] T. J. Monks, R. P. Hanzlik, G. M. Cohen, D. Ross, and D. G. Graham, "Quinone chemistry and toxicity," Toxicology and Applied Pharmacology, vol. 112, no. 1, pp. 2-16, 1992.

[89] M. O. F. Goulart, P. Falkowski, T. Ossowski, and A. Liwo, "Electrochemical study of oxygen interaction with lapachol and its radical anions," Bioelectrochemistry, vol. 59, no. 1-2, pp. 85-87, 2003.

[90] A. V. Pinto and S. L. De Castro, "The trypanocidal activity of naphthoquinones: a review," Molecules, vol. 14, no. 11, pp. 4570-4590, 2009.

[91] T. J. Monks and D. C. Jones, "The metabolism and toxicity of quinones, quinonimines, quinone methides, and quinonethioethers," Current Drug Metabolism, vol. 3, no. 4, pp. 425438, 2002.

[92] R. Munday, B. L. Smith, and C. M. Munday, "Structureactivity relationships in the haemolytic activity and nephrotoxicity of derivatives of 1,2- and 1,4-naphthoquinone," Journal of Applied Toxicology, vol. 27, no. 3, pp. 262-269, 2007.

[93] R. Munday, "Autoxidation of naphthohydroquinones: effects of $\mathrm{pH}$, naphthoquinones and superoxide dismutase," Free Radical Research, vol. 32, no. 3, pp. 245-253, 2000.

[94] J. L. Bolton, M. A. Trush, T. M. Penning, G. Dryhurst, and T. J. Monks, "Role of quinones in toxicology," Chemical Research in Toxicology, vol. 13, no. 3, pp. 135-160, 2000.

[95] B. Hazra, M. Das Sarma, and U. Sanyal, "Separation methods of quinonoid constituents of plants used in oriental traditional medicines," Journal of Chromatography B, vol. 812, no. 1-2, pp. 259-275, 2004.

[96] S. L. Croft, J. Hogg, W. E. Gutteridge, A. T. Hudson, and A. W. Randall, "The activity of hydroxynaphthoquinones against Leishmania donovani," Journal of Antimicrobial Chemotherapy, vol. 30, no. 6, pp. 827-832, 1992.

[97] A. T. Hudson, "Atovaquone-a novel broad-spectrum antiinfective drug," Parasitology Today, vol. 9, no. 2, pp. 66-68, 1993.

[98] S. Sepúlveda-Boza and B. K. Cassels, "Plant metabolites active against Trypanosoma cruzi," Planta Medica, vol. 62, no. 2, pp. 98-105, 1996.

[99] P. Arenas, "Medicine and magic among the Maka indians of the Paraguayan Chaco," Journal of Ethnopharmacology, vol. 21, no. 3, pp. 279-295, 1987.

[100] J. W. Bastien, "Pharmacopeia of Qollahuaya Andeans," Journal of Ethnopharmacology, vol. 8, no. 1, pp. 97-111, 1983.

[101] C. F. de Santana, O. de Lima, I. L. d’ Albuquerque, A. L. Lacerda, and D. G. Martins, "Antitumoral and toxicological properties of extracts of bark and various wood components of Pau d'arco (Tabebuia avellanedae)," Revista do Instituto de Antibioticos, vol. 8, no. 1, pp. 89-94, 1968.

[102] A. Boveris, R. Docampo, J. F. Turrens, and A. O. M. Stoppani, "Effect of $\beta$-lapachone on superoxide anion and hydrogen peroxide production in Trypanosoma cruzi," Biochemical Journal, vol. 175, no. 2, pp. 431-439, 1978.

[103] F. S. Cruz, R. Docampo, and W. De Souza, "Effect of $\beta$ lapachone on hydrogen peroxide production in Trypanosoma cruzi," Acta Tropica, vol. 35, no. 1, pp. 35-40, 1978.
[104] R. Docampo, F. S. Cruz, A. Boveris, R. P. Muniz, and D. M. Esquivel, "Lipid peroxidation and the generation of free radicals, superoxide anion and hydrogen peroxide in $\beta$-lapachone treated Trypanosoma cruzi epimastigotes," Archives of Biochemistry and Biophysics, vol. 186, no. 2, pp. 292-297, 1978.

[105] S. G. Goijman and A. O. M. Stoppani, "Effects of $\beta$-lapachone, a peroxide-generating quinone, on macromolecule synthesis and degradation in Trypanosoma cruzi," Archives of Biochemistry and Biophysics, vol. 240, no. 1, pp. 273-280, 1985.

[106] M. P. Molina Portela, S. H. F. Fernandez Villamil, L. J. Perissinotti, and A. O. M. Stoppani, "Redox cycling of o-naphthoquinones in trypanosomatids. Superoxide and hydrogen peroxide production," Biochemical Pharmacology, vol. 52, no. 12, pp. 1875-1882, 1996.

[107] A. O. M. Stoppani, "The chemotherapy of Chagas disease," Medicina, vol. 59, supplement 2, pp. 147-165, 1999.

[108] R. Docampo, J. N. Lopes, F. S. Cruz, and W. De Souza, "Trypanosoma cruzi: ultrastructural and metabolic alterations of epimastigotes by $\beta$ lapachone," Experimental Parasitology, vol. 42, no. 1, pp. 142-149, 1977.

[109] J. N. Lopes, F. S. Cruz, R. Docampo et al., "In vitro and in vivo evaluation of the toxicity of 1,4-naphtoquinone and 1,2-naphthoquinone derivatives against Trypanosoma cruzi," Annals of Tropical Medicine and Parasitology, vol. 72, no. 1, pp. 523-531, 1978.

[110] A. V. Pinto, M. C. F. R. Pinto, M. A. Aguiar, and R. S. Capella, "Transformações do lapachol em nafto-[1,2-b]furanaquinonas naturais," Anais da Academia Brasileira de Ciências, vol. 54, pp. 115-118, 1982.

[111] A. V. Pinto, V. F. Ferreira, M. C. F. R. Pinto, and L. U. Mayer, "Reaction of 2-amino-1,4-naphthoquinone derivatives with dimethyl acetylenedicarboxylate," Synthetic Communications, vol. 15, no. 1, pp. 1181-1189, 1985.

[112] C. C. Lopes, R. S. C. Lopes, A. V. Pinto, and P. R. R. Costa, "Efficient synthesis of cytotoxic quinones: 2-acetyl4H,9H-naphtho[2,3-b] furan-4,9-dione," Journal of Heterocyclic Chemistry, vol. 21, no. 2, pp. 621-622, 1984.

[113] J. P. Chaves, M. C. F. R. Pinto, and A. V. Pinto, "Heterocyclics from quinones. I-reaction of lapachol with primary alkyl amines," Journal of Brazilian Chemical Society, vol. 1, no. 3, pp. 21-27, 1990.

[114] S. L. de Castro, M. C. Pinto, and A. V. Pinto, "Screening of natural and synthetic drugs against Trypanosoma cruzi. 1. Establishing a structure/activity relationship," Microbios, vol. 78, no. 315, pp. 83-90, 1994.

[115] A. V. Pinto, C. N. Pinto, M. D. C. F. R. Pinto, R. S. Rita, C. A. C. Pezzella, and S. L. De Castro, "Trypanocidal activity of synthetic heterocyclic derivatives of active quinones from Tabebuia sp," Arzneimittel-Forschung/Drug Research, vol. 47, no. 1, pp. 74-79, 1997.

[116] C. N. Pinto, A. P. Dantas, K. C. G. De Moura et al., "Chemical reactivity studies with naphthoquinones from Tabebuia with anti-trypanosomal efficacy," Arzneimittel-Forschung, vol. 50, no. 12, pp. 1120-1128, 2000.

[117] C. Neves-Pinto, V. R. S. Malta, M. D. C. F. R. Pinto, R. H. A. Santos, S. L. De Castro, and A. V. Pinto, "A trypanocidal phenazine derived from $\beta$-lapachone," Journal of Medicinal Chemistry, vol. 45, no. 10, pp. 2112-2115, 2002.

[118] K. C. G. Moura, F. S. Emery, C. Neves-Pinto et al., "Synthesis and trypanocidal activity of naphthoquinones isolated from Tabebuia and heterocyclic derivatives: a review from an interdisciplinary study," Journal of Brazilian Chemical Society, vol. 12, no. 3, pp. 325-338, 2001. 
[119] K. C. G. De Moura, K. Salomão, R. F. S. Menna-Barreto et al., "Studies on the trypanocidal activity of semi-synthetic pyran $[b-4,3]$ naphtho[1,2-d]imidazoles from $\beta$-lapachone," European Journal of Medicinal Chemistry, vol. 39, no. 7, pp. 639-645, 2004.

[120] E. N. da Silva Jr., R. F. S. Menna-Barreto, M. D. C. F. R. Pinto et al., "Naphthoquinoidal [1,2,3]-triazole, a new structural moiety active against Trypanosoma cruzi," European Journal of Medicinal Chemistry, vol. 43, no. 8, pp. 1774-1780, 2008.

[121] E. N. da Silva Jr., T. T. Guimarães, R. F. S. Menna-Barreto et al., "The evaluation of quinonoid compounds against Trypanosoma cruzi: synthesis of imidazolic anthraquinones, nor- $\beta$-lapachone derivatives and $\beta$-lapachone-based 1,2,3triazoles," Bioorganic and Medicinal Chemistry, vol. 18, no. 9, pp. 3224-3230, 2010.

[122] E. N. da Silva Jr., M. C.B.V. de Souza, M. C. Fernandes et al., "Synthesis and anti-Trypanosoma cruzi activity of derivatives from nor-lapachones and lapachones," Bioorganic and Medicinal Chemistry, vol. 16, no. 9, pp. 5030-5038, 2008.

[123] R. S. F. Silva, E. M. Costa, U. L. T. Trindade et al., "Synthesis of naphthofuranquinones with activity against Trypanosoma cruzi," European Journal of Medicinal Chemistry, vol. 41, no. 4, pp. 526-530, 2006.

[124] R. F. S. Menna-Barreto, R. L. S. Gonçalves, M. Costa et al., "The activity against Trypanosoma cruzi of novel synthetic naphthoquinones is mediated by mitochondrial dysfunction and oxidative stress," Free Radical Biology \& Medicine, vol. 47, no. 5, pp. 644-653, 2009.

[125] R. F.S. Menna-Barreto, A. Henriques-Pons, A. V. Pinto, J. A. Morgado-Diaz, M. J. Soares, and S. L. De Castro, "Effect of a $\beta$-lapachone-derived naphthoimidazole on Trypanosoma cruzi: identification of target organelles," Journal of Antimicrobial Chemotherapy, vol. 56, no. 6, pp. 1034-1041, 2005.

[126] R. F. S. Menna-Barreto, J. R. Corrêa, A. V. Pinto, M. J. Soares, and S. L. De Castro, "Mitochondrial disruption and DNA fragmentation in Trypanosoma cruzi induced by naphthoimidazoles synthesized from $\beta$-lapachone," Parasitology Research, vol. 101, no. 4, pp. 895-905, 2007.

[127] R. F. S. Menna-Barreto, J. R. Corrêa, C. M. Cascabulho et al., "Naphthoimidazoles promote different death phenotypes in Trypanosoma cruzi," Parasitology, vol. 136, no. 5, pp. 499-510, 2009.

[128] R. F. S. Menna-Barreto, K. Salomão, A. P. Dantas et al., "Different cell death pathways induced by drugs in Trypanosoma cruzi: an ultrastructural study," Micron, vol. 40, no. 2, pp. 157-168, 2009.

[129] F. Irigoín, L. Cibils, M. A. Comini, S. R. Wilkinson, L. Flohé, and R. Radi, "Insights into the redox biology of Trypanosoma cruzi: trypanothione metabolism and oxidant detoxification," Free Radical Biology and Medicine, vol. 45, no. 6, pp. 733-742, 2008.

[130] R. F. S. Menna-Barreto, D. G. Beghini, A. T. S. Ferreira, A. V. Pinto, S. L. De Castro, and J. Perales, "A proteomic analysis of the mechanism of action of naphthoimidazoles in Trypanosoma cruzi epimastigotes in vitro," Journal of Proteomics, vol. 73, no. 12, pp. 2306-2315, 2010.

[131] J. H. Mckerrow, P. S. Doyle, J. C. Engel et al., "Two approaches to discovering and developing new drugs for Chagas disease," Memórias do Instituto Oswaldo Cruz, vol. 104, no. 1, pp. 263$269,2009$.

[132] Y. Ozaki, M. E. Guariento, and E. A. De Almeida, "Quality of life and depressive symptoms in Chagas disease patients," Quality of Life Research, vol. 20, no. 1, pp. 133-138, 2011.

[133] W. de Oliveira Jr., "All-around care for patients with Chagas disease: a challenge for the XXI century," Memórias do Instituto Oswaldo Cruz, vol. 104, no. 1, pp. 181-186, 2009. 

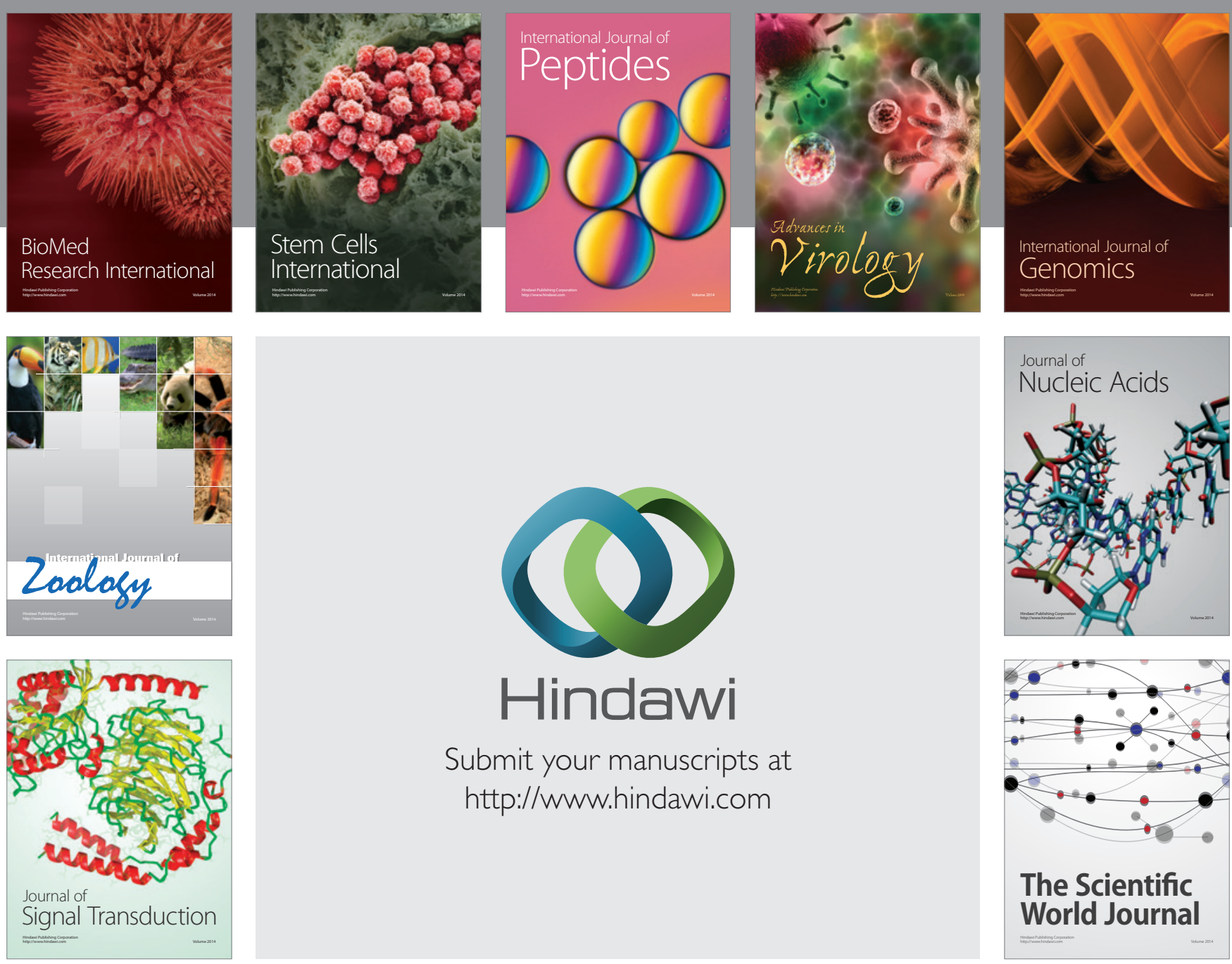

Submit your manuscripts at

http://www.hindawi.com
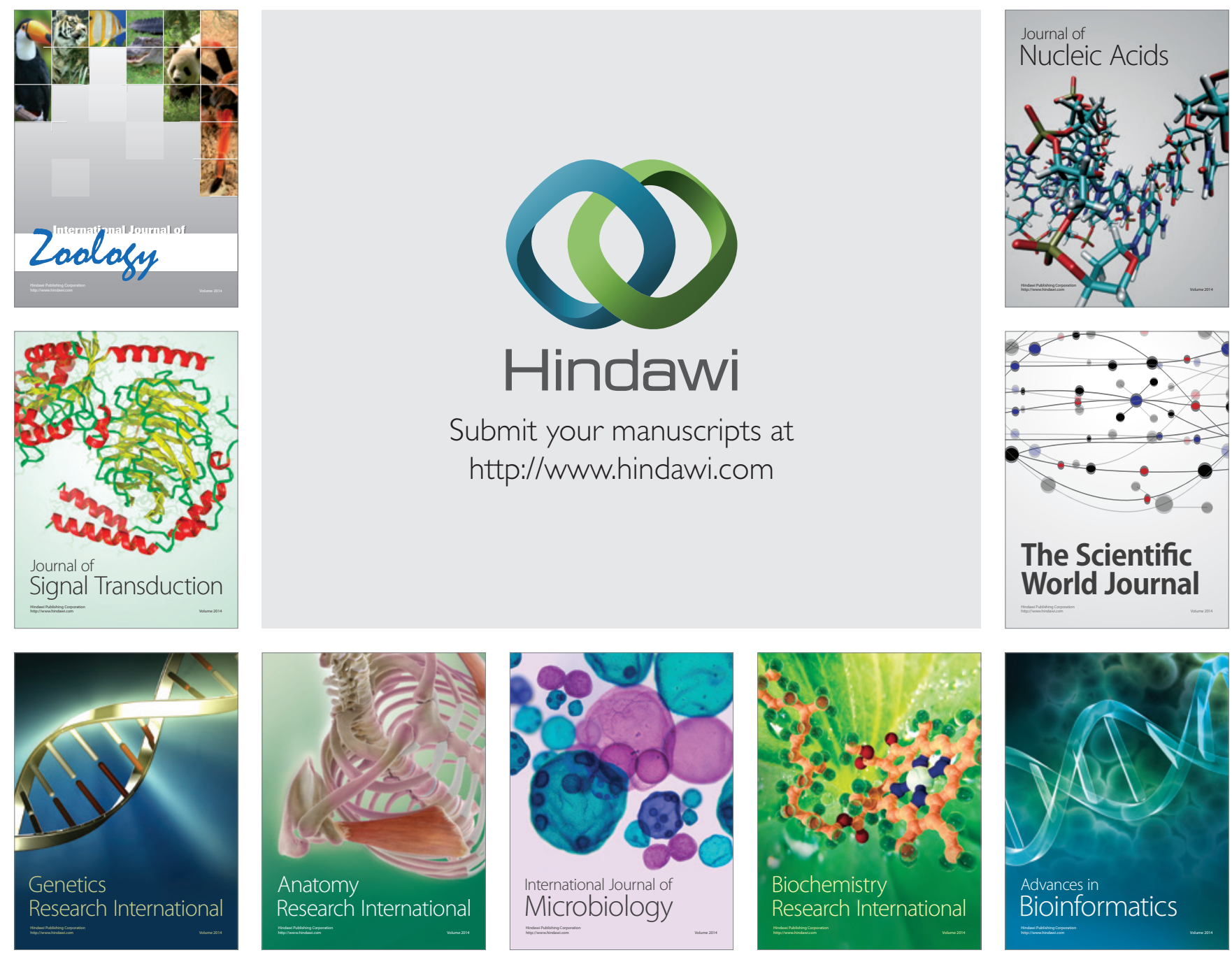

The Scientific World Journal
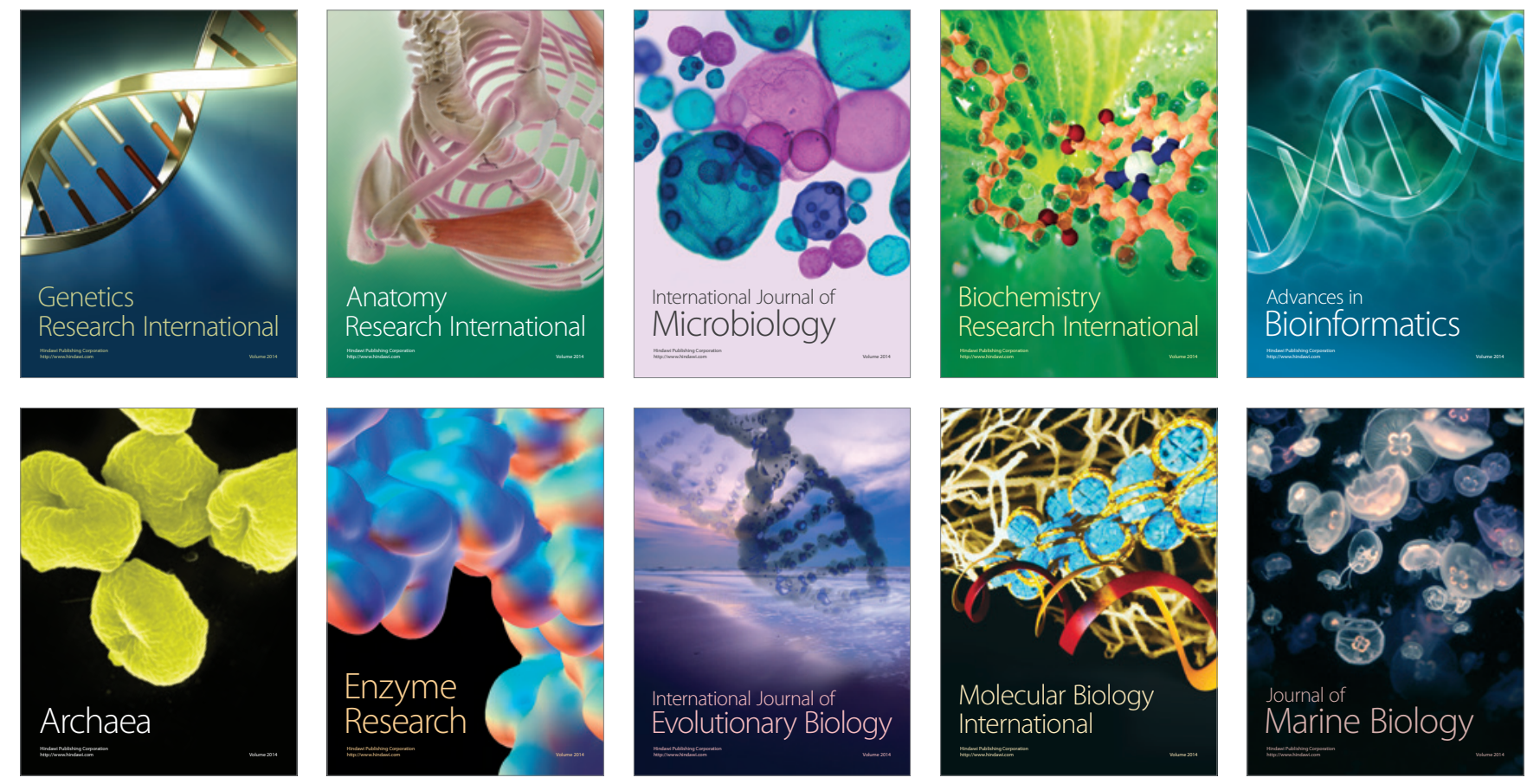